\title{
CrimRxiv
}

\section{Organizational support for frontline harm reduction and systems navigation work among workers with living and lived experience: qualitative findings from British Columbia, Canada}

Alissa Greer, J. A. Buxton, B. Pauly, V. Bungay

Published on: Jun 05, 2021

DOI: $10.21428 / \mathrm{cb} 6 \mathrm{ab} 371.219136 \mathrm{ee}$

License: Creative Commons Attribution 4.0 International License (CC-BY 4.0) 
